\title{
Article
}

\section{A New Method for Monitoring Gears Surface Failures Using Enhanced Image Registration Approach}

Onsy, Ahmed, Fouad, Mohamed, Shaw, Brian and Dansereau, Richard M.

Available at http://clok.uclan.ac.uk/18511/

Onsy, Ahmed ORCID: 0000-0003-0803-5374, Fouad, Mohamed, Shaw, Brian and Dansereau, Richard M. (2014) A New Method for Monitoring Gears Surface Failures Using Enhanced Image Registration Approach. SAE International Journal of Aerospace, 7 (1). pp. 182-189.

It is advisable to refer to the publisher's version if you intend to cite from the work. http://dx.doi.org/10.4271/2014-01-9003

For more information about UCLan's research in this area go to http://www.uclan.ac.uk/researchgroups/ and search for <name of research Group>.

For information about Research generally at UCLan please go to http://www.uclan.ac.uk/research/

All outputs in CLoK are protected by Intellectual Property Rights law, including Copyright law. Copyright, IPR and Moral Rights for the works on this site are retained by the individual authors and/or other copyright owners. Terms and conditions for use of this material are defined in the policies page.

\section{CLoK}

Central Lancashire online Knowledge www.clok.uclan.ac.uk

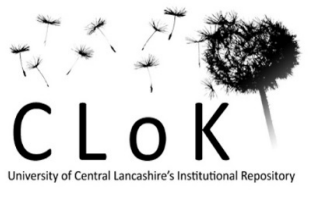




\title{
A New Method for Monitoring Gears Surface Failures Using Enhanced Image Registration Approach
}

\author{
Ahmed Onsy and Mohamed Fouad \\ MTC \\ Brian Shaw \\ Newcastle University \\ Richard M. Dansereau \\ Carleton University
}

\begin{abstract}
In this paper, we present an image registration approach to cope with inter-image illumination changes of arbitrary shape in order to monitor the development of micro-pitting in transmission gears. Traditional image registration approaches do not typically account for inter-image illumination variations that negatively affect the geometric registration precision. Given a set of captured images of gear surface degradation with different exposure times and geometric deformations, the correlation between the resulting aligned images is compared to a reference one. The presented image registration approach is used with an online health monitoring system involving the analysis of vibration, acoustic emission and oil debris to follow the development of micro-pitting in transmission gears. The proposed monitoring system achieves more registration precision compared to competing systems. This paper experimentally validates the system's capabilities to detect early gear defects and reliably identify the gradual development of micro-pitting in gears, so that it could be used in predictive health monitoring (PHM) systems and overcome the disadvantages of the most commonly used methods, such as gear flank profile scanning, replica sample analysis and conventional image analysis.
\end{abstract}

CITATION: Onsy, A., Fouad, M., Shaw, B., and Dansereau, R., "A New Method for Monitoring Gears Surface Failures Using Enhanced Image Registration Approach," SAE Int. J. Aerosp. 7(1):2014, doi:10.4271/2014-01-9003.

\section{INTRODUCTION}

Surface fatigue failure occurs in geared transmission systems due to factors such as high contact stress, and monitoring its progression is vital if the eventual failure of the tooth flank is to be prevented. Pitting is one of the main failure mechanisms in gears. It occurs as a result of a high level of Hertzian contact stress that the surface cannot withstand. Pitting develops from initial (micro) pitting to progressive (macro) pitting [1]. In order to trace the development of gear surface failures, a suitable assessment method is required to correlate the characteristics of the monitoring technique with the condition of the gear surface. Three methods are most commonly used: gear flank profile scanning, replica sample analysis, and conventional image analysis. Gear flank profile scanning is the most accurate method, but it requires not only expensive equipment but also the removal of gears from the test rig. Their subsequent replacement in the rig changes the contact area of the gear teeth, thus introducing another variable into the testing process [2].
The second method is moderately effective in assessing change in the gear flanks, and is achieved by injecting a replication medium into the tooth face width, which cures within one minute. The replica samples are then extracted and inspected under a stereo microscope with a suitable objective lens in order to quantify the extent of propagated surface damage. The replica sample analysis is based on the focus area on the replica of the tooth flanks, which may not be developed during the testing period. This is a 2-D method of analysis which includes a degree of uncertainty in the results, in some tests varying by about $5-10 \%$ from the actual change in the signature of monitored signals $[\underline{3}, \underline{4}, \underline{5}, \underline{6}]$. Conventional image analysis is achieved by taking a sequence of photographs of the gear flanks at the end of each testing period, with the images then analyzed manually. This is the cheapest method; nevertheless it is often inaccurate and human error affects the results.

Other research work has assessed the development of surface failure by measuring the gear flanks themselves using visual inspection. Based on comparative studies, it is worth noting 
that this method could be used for an approximate analysis and is suitable for examining advanced phases of surface fatigue failure, such as macro-pitting and scuffing. However it cannot be used to assess the development of micro-pitting. So there is a clear need to introduce a new method which is not only reliable and based on an automated technique but is also inexpensive.

This paper presents an approach for gear surface evaluation using an image registration technique with an online health monitoring system. Image registration (IR) is a process used to determine the point-by-point correspondence between two views of a scene and the transformation to align these correspondences. The IR of a set of images is a common pre-processing step in many applications, such as remotesensing techniques, performing super-resolution enhancement, and generating panoramic images. For these and similar applications, such as this ongoing research, a high level of accuracy in sub-pixel registration is necessary to achieve satisfactory post-processing results $[\underline{7}, \underline{8}]$.

Traditional image registration approaches do not typically account for changes in and the movement of light sources, resulting in differences in inter-image illumination with arbitrary shape. In addition, these approaches typically use a leastsquares estimator that is sensitive to outliers, and variations in inter-image illumination are often large enough to act as outliers. A primary problem in many image registration scenarios is that non-geometrical transform variations within the image set often also exist. These variations are caused by many factors, including changes in lighting, the motion/ deformations of features in the scene, changes in occluded and occluding objects, and changes in exposure, aperture, focus, lens distortion or other photometric factors. In the case of gear flank photos, local illumination variations (LIV) in terms of imaging modality, resolution, and information content exist due to the capture of various images of the same scene at different exposure times. As well, the changes in micro-pitting over time also act as a non-geometrical transform since these new features appear in subsequent images. These changes, if small and different between the two images, should also be ignored in the image registration as they have the potential to degrade the registration. In other words, new micro-pitting would act as an outlier as well in the registration process as will be shown later.

The impact of LIV on geometric image registration (GIR) has been studied and a generalized model has been developed to handle image sets with arbitrarily-shaped local illumination variations (ASLIV) using a robust M-estimator with the Huber function [7]. The latter, however, assigns a constant weight to high residuals, thus still impacting on geometric registration precision (GRP). Therefore, the bisquare function is used in the M-estimation, as it cancels out the effect of high residuals and is thus less sensitive to outliers, consequently improving the GRP []].
To prevent an unexpected failure due to the progression of localized defects, it is necessary to monitor the initiation and progression of pitting. Three monitoring techniques are currently used in gear transmission systems, involving the analysis of vibration, acoustic emissions and oil debris. Researchers have studied these techniques and have produced results highlighting the various advantages of the different techniques. However, only a few studies have considered surface contact failure. Furthermore, many have been based on artificially induced gear faults and not on natural degradation failures. The present authors have investigated both bending and surface contact fatigue failures in both spur and helical gears $[\underline{2}, \underline{3}, \underline{4}, \underline{5}, \underline{6}, \underline{9}, \underline{10}]$, and this study builds on previous research to enhance methods of evaluating gear surfaces. Vibration monitoring can be used to acquire information about transmission components under normal operating conditions that would otherwise be inaccessible. The authors $[\underline{2}, \underline{3}, \underline{4}, \underline{5}, \underline{6}, \underline{9}, \underline{10}]$ exploited TDA statistical information extracted from vibration signals to monitor micro-pitting in gears, and it was concluded that using vibration level monitoring over the frequency bands as an indicator of gear pitting rate was a useful monitoring technique. During the operation of power transmission systems, wear debris is generated and transported by the oil. The identification and classification of this debris can help to understand the wear mechanism and relate it to a specific wear process. Oil debris analysis (ODA) can be used to determine whether or not the transmission requires maintenance and it can serve as a prognostic indicator in power transmission system health monitoring. Onsy et al. [일 10$]$ concluded that the use of online ODA provided an accurate automated method to monitor gear surface failures. The effectiveness of acoustic emission (AE), vibration, and ODA monitoring has been experimentally investigated, such that combinations of two or more monitoring techniques (AE, vibration and oil debris) using sensor fusion approaches to study the ability to predict the condition of geared transmission systems whilst conducting fatigue tests that allow gear pitting to occur under normal running conditions $[\underline{2}, \underline{3}, \underline{4}, \underline{5}, \underline{6}, \underline{9}]$. Onsy et al. concluded that the use of all three techniques (acoustic emission, vibration analysis and ODA) not only offer an earlier indication of gear damage, but can also predict the onset of failure which enhances the analytical results derived for the spur gear transmission system investigated.

\section{EXPERIMENTAL TEST RIG}

A back-to-back gear test rig developed at Newcastle University was used for this research. The rig comprises a $75 \mathrm{~mm}$ centre distance back-to-back test gearbox connected to a slave gearbox. The test gears, consisting of a pinion and a wheel, are lubricated by a pressurized spray of oil pumped. The system is driven by a $5.5 \mathrm{~kW}$ variable speed electric motor controlled by an inverter to provide a speed variation of $0-6000$ rpm. Testing torque is generated through a hydraulic mechanism and a slave gearbox is used to apply the load. The rig can generate a load torque on the test gears in the range of $0-600 \mathrm{Nm}$. The torque is measured using calibrated strain 

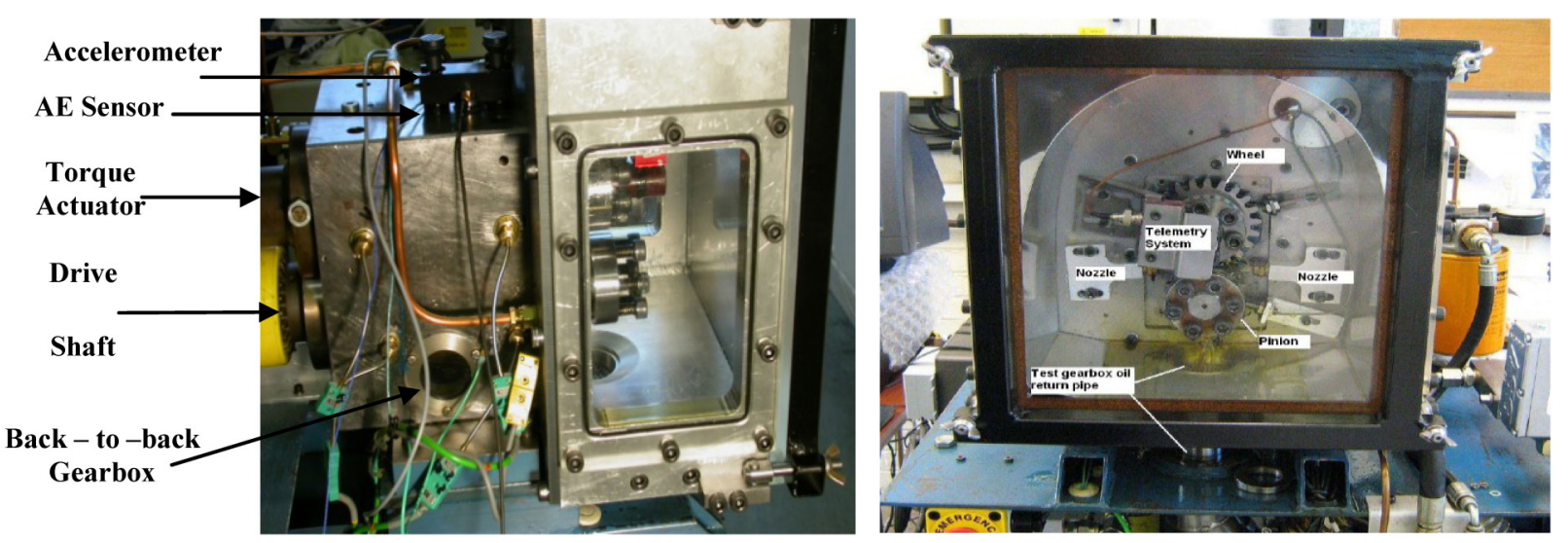

Figure 1. Newcastle University 75 mm centre distance back-to-back gear test rig

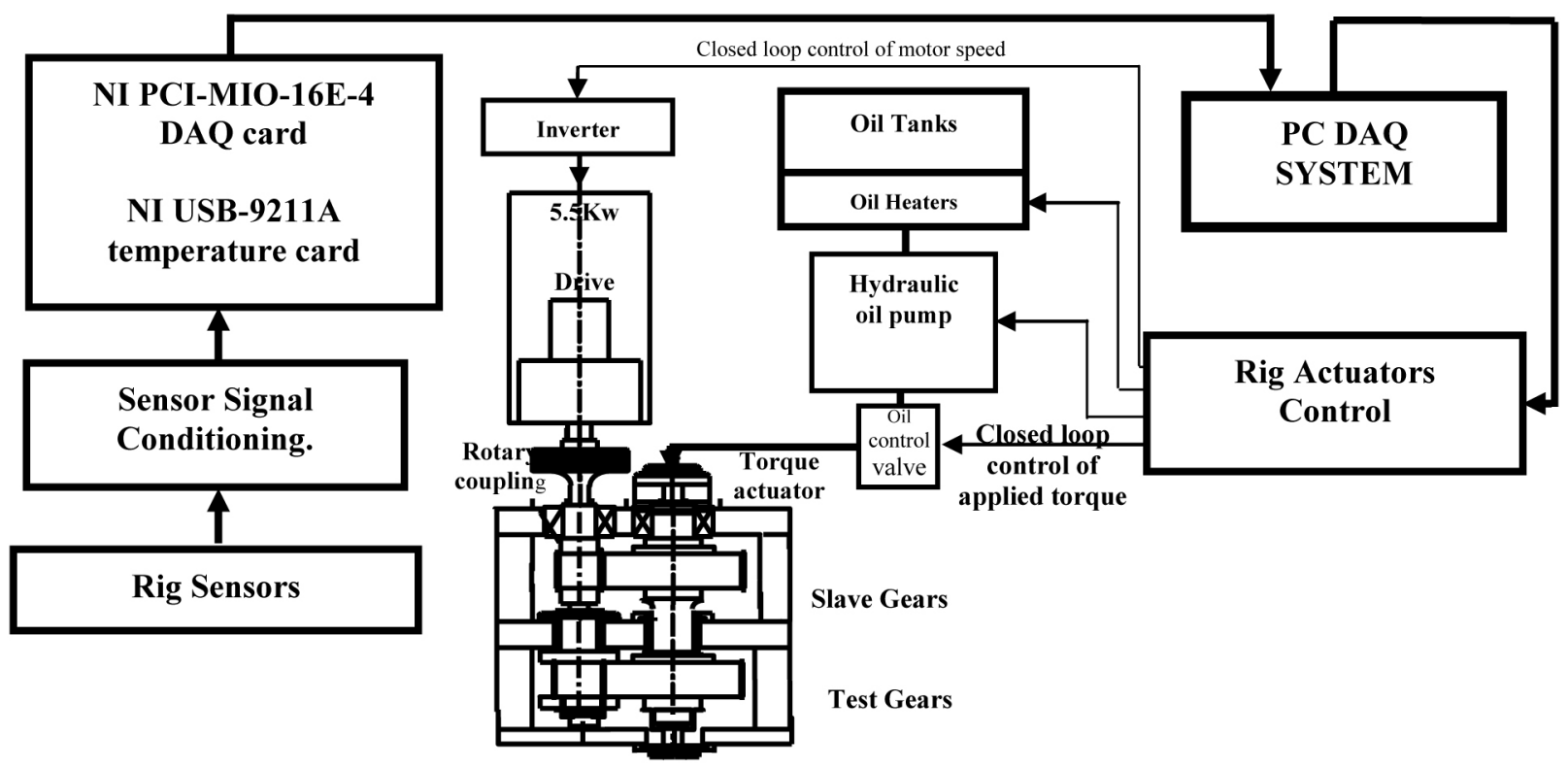

Figure 2. $75 \mathrm{~mm}$ test rig sensor -actuation system layout.

gauges installed on the wheel shaft and the measured torque values are transmitted to the control program by telemetry in order to provide closed loop torque control of the actual load on the gear itself. The test rig, as shown in Figure 1, is controlled using National Instruments (NI) LabVIEW which consists of a PCI-MIO-16E-4 E series data acquisition card (NI) and $250 \mathrm{ksps}$ sampling rate. Temperature is monitored using a USB-9211A temperature data acquisition card (NI). Three oil heaters and a water cooler are used to ensure that the running oil is maintained at a constant temperature during the tests. Temperatures were measured at three locations: rig oil tank, test gear bearing and slave gear bearing. Oil pressure and flow rates were also measured. A gear tooth trigger sensor was installed adjacent to the pinion test gear to ensure that tooth failure could be recorded. The input shaft speed and motor current were also monitored as a precaution. The test rig software provided the flexibility to change the control algorithm of the parameters measured according to the test conditions using LabVIEW's scalable architecture features. The test rig sensor-actuation system layout is shown in Figure 2. A pair of spur gears was tested under closely controlled conditions. The test gears were $4.2 \mathrm{~mm}$ module spur gears with a 14/21 gear ratio and a $10 \mathrm{~mm}$ nominal contact width.

\section{ONLINE HEALTH MONITORING TECHNIQUES}

A power transmission health monitoring system (HMS) has been developed and is currently being validated to recognize failures, including gear surface failure by micro-pitting. The system was developed for trend monitoring to show how parameters change from a base line signature. The system monitors vibration and oil debris. Various methods can be used to analyze vibration, such as time domain analysis (TDA), frequency domain and time-frequency domain analysis. Also, continuous AE monitoring and transient analysis can be used. The system is capable of on-line monitoring, automatic measurement and analysis and any changes in gear condition and degradation during operation can also be identified. The HMS algorithms are discussed in detail in [2]. 
The image registration approach used in this paper, with the bisquare function is applied to the captured images of the pinion and wheel gear flanks. These captured images may have variations in exposure, lighting, etc. at each image capture that would need to be appropriately considered during the image registration. Then, each resulting aligned image is compared to a reference image, introducing an index to show how they are correlated to each other. This index is used as a monitoring indicator for the progression of the micro-pitting on the gears flank. The image registration approach compensates for arbitrarily-shaped inter-image illumination variations, which are processed using robust M-estimators tuned to that region.

The idea behind gear failure analysis using IR relies on determining the correlation between each image, $I_{1}$, and a reference image, $I_{2}$, captured for a specific tooth flank, before the operation begins. This correlation can be obtained by determining an image quality metric between two aligned images. The lower the value of the image quality metric, the lower the correlation is between the two aligned images. In our case, each image is anticipated to become increasingly different from its precedent as the micro-pitting proceeds. It is also known a priori that $I_{1}$ and $I_{2}$ are definitely different from each other in two respects. Firstly, $I_{1}$ may be taken from another perspective, so that it would display geometric deformations compared to $I_{2}$. Secondly, some local illumination variations would appear in $I_{1}$ compared to $I_{2}$ due to the impacts of the progression of micro-pitting as well as different capturing times (i.e., the time at which $I_{1}$ is captured). Therefore, each image has to be geometrically and photometrically aligned with respect to a reference image in order to determine their correlation index. Ultimately, the resulting correlation values for all images, captured at increasing numbers of cycles, are expected to fall in a decreasing order.

The image registration approach used in this paper in order to achieve geometric alignment jointly with compensation for local illumination changes between a reference image $I_{2}$ and sensed image $I_{1}$ taken later, has been detailed in []. Assuming that two $N \times M$ images, $I_{1}$ and $I_{2}$, were captured of the same scene at two different times, the images may have distinct illumination regions with arbitrary shapes. We can summarize the used image registration approach as follows. First, we suggest use of a robust estimator, such as the $M$-estimator, for each illumination region to cope with its own residuals to ultimately improve the GRP. Meanwhile, the approach imposes weights in the segmentation to the points located on or near the boundary of each illumination region due to mis-segmentation. These two steps distinguish the proposed approach in this paper with that shown in [11], thus further improving the GRP.

A minimization problem can be cast as,

$$
\min _{\boldsymbol{\Phi}}\left\{\sum_{\mathbf{x}}\left(\sum_{j=1}^{J} \gamma_{j} S_{j}+\gamma_{j}\left[1-\left(1-\left(\frac{F_{j} \odot E_{j}\left(\boldsymbol{\Phi}_{\mathbf{i}: \mathbf{x}}\right.}{\alpha_{j}}\right)^{2}\right)^{3}\right]\right)\right\},
$$

Where $\Phi$ is the unknown vector, needed to be estimated, including the geometric and illumination parameters, between $I_{1}$ and $I_{2} . E_{j}(\Phi ; x)$ is an element in a residual matrix $E_{j}(\Phi)$, between $I_{1}$ and $I_{2}$, located at position $\mathrm{x} \in \mathrm{R}_{\mathrm{j}}$, where $R_{\mathrm{j}}$ denotes an illumination region, $\forall 1 \leq \mathrm{j} \leq \mathrm{J}$, and $\mathrm{J}$ denotes the number of distinct illumination regions. $\alpha_{j}$ and $\gamma_{j}$ are positive tuning thresholds, where $\alpha_{j}=\sqrt{6 \gamma_{j}} . S_{j}$ and $F_{j}$ denote the high- and low-residual selective matrices, respectively. The unknown vector $\Phi$ can be iteratively estimated using the GaussianNewton method to solve the non-linear minimization problem in (1). An aligned image, $l_{a}$, is obtained by applying the estimated vector $\Phi$ to the sensed image $I_{1}$. Then, each aligned image, $I_{a}$, is compared to the reference one, $I_{2}$, obtaining their correlation value using, e.g., complex wavelet structural similarity (CWSSIM) index [12]. The CWSSIM index is between 0 and 1, where 1 is a perfect match and 0 is a complete mismatch. In the case of developing micro-pitting, incremental values of mismatch are expected. A new feature named the failure index $(\mathrm{FI})$ is introduced to show the incremental development of the mismatch values, such that

$$
\mathrm{FI}=1-\mathrm{CWSSIM} \text {. }
$$

For further details about the image registration approach used, a reader can be referred to []].

\section{RESULTS AND DISCUSSION}

\section{A- Gear Failure Analysis}

Observations of the progression of micro-pitting on a specific tooth flank of each gear were carried out by capturing an image every $8 \times 10^{6}$ cycles for both test pinion and wheel gear flanks (marked tooth (no. 1)), and these images were taken as a record showing the progression of damage as a result of continuous running at relatively high torque / contact stress. Figures 3 and $\underline{4}$ show photographs of test gears taken at the beginning of test, and after completion of running at $210 \mathrm{Nm}$, $310 \mathrm{Nm}$ and $350 \mathrm{Nm}$ respectively, and the gear damage observed during inspection is shown in Table 1.

A Matlab algorithm has been developed to apply the image registration approach used in this paper and to then compute the $\mathrm{FI}$, shown in (2), using an array of images as shown in Figures 4 and $\underline{5}$. The algorithm computed the $\mathrm{FI}$ at $13.7 \times 10^{6}$ cycles for the pinion gear of 0.08 while for the wheel gear of 0.16 , which is higher than the pinion FI value. Also, at $75.78 \times 10^{6}$ cycles the $\mathrm{FI}$ value for the pinion is 0.25 while for the wheel is 0.35 , which is again higher than the pinion $\mathrm{FI}$ value. Figure 5 illustrates the FI versus number of cycles, showing that the micro-pitting progressed gradually during the testing period using the proposed approach is more closer to the vibration and oil debris analysis results, compared to that of the BMASLIV approach [11] that uses the IR approach in [7]. The FI results are confirmed by the gear metrology results as shown in Figures 6 and $\underline{7}$. 

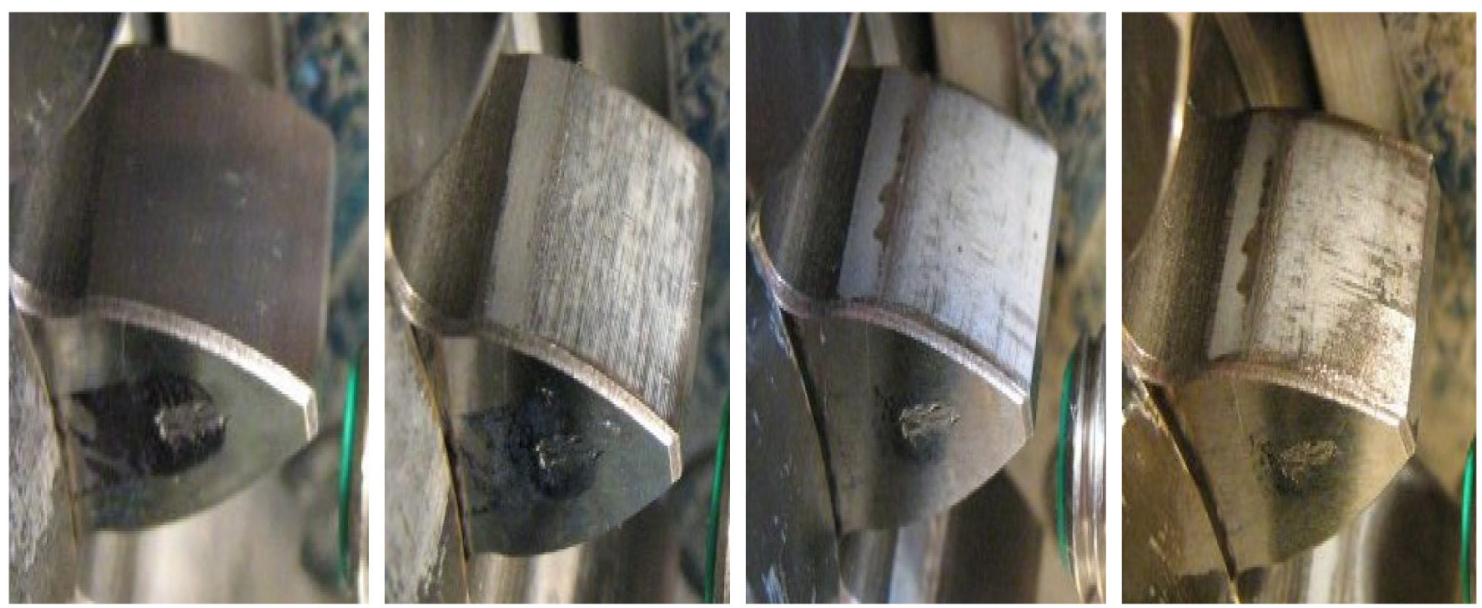

Figure 3. Pinion flanks showing: (a) Before gear test (b) Micro-pitting after testing at $210 \mathrm{Nm}\left(13.7 \times 10^{6}\right.$ cycles) (c) Micro-pitting after testing at $310 \mathrm{Nm}$ $\left(75.76 \times 10^{6}\right.$ cycles) (d) Micro-pitting, small-scale macro pitting and scuffing after testing at $350 \mathrm{Nm}\left(75.78 \times 10^{6}\right.$ cycles $)$
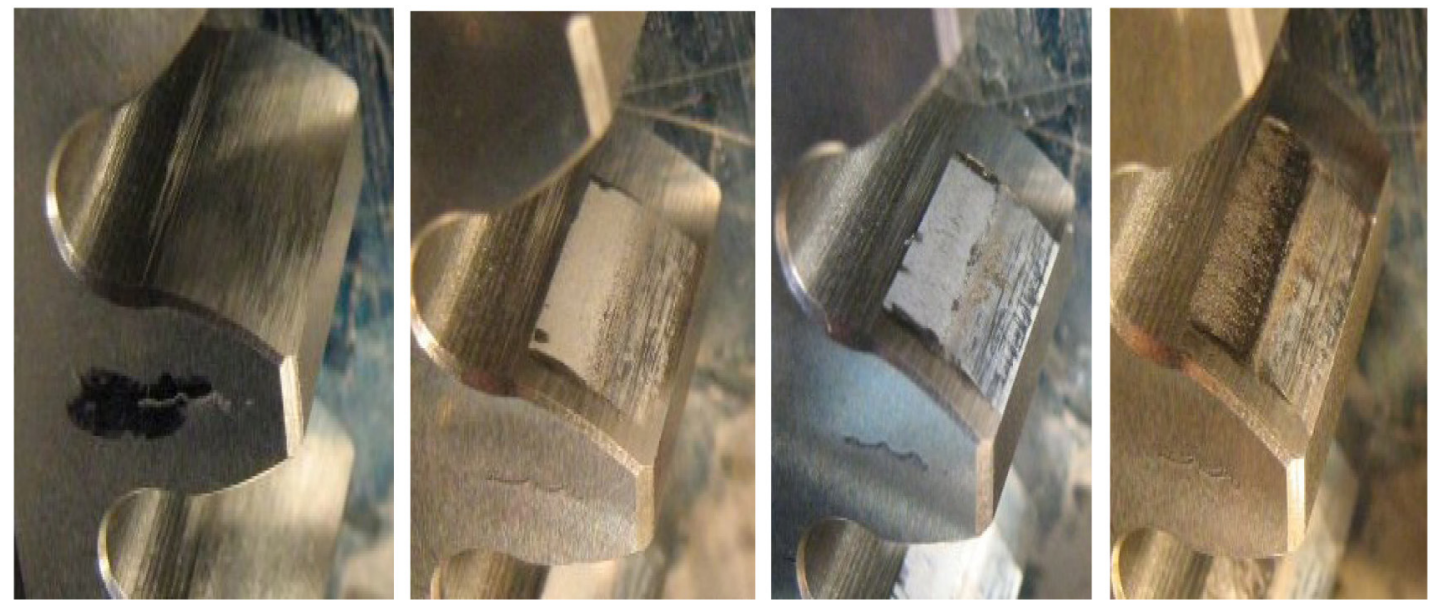

Figure 4. Wheel flanks showing: (a) Before gear test (b) Micro-pitting after testing at $210 \mathrm{Nm}\left(13.7 \times 10^{6}\right.$ cycles) (c) Micro-pitting small-scale macro pitting after testing at $310 \mathrm{Nm}\left(75.76 \times 10^{6}\right.$ cycles) (d) Micro-pitting, small-scale macro pitting and scuffing after testing at $350 \mathrm{Nm}\left(75.78 \times 10^{6} \mathrm{cycles}\right)$

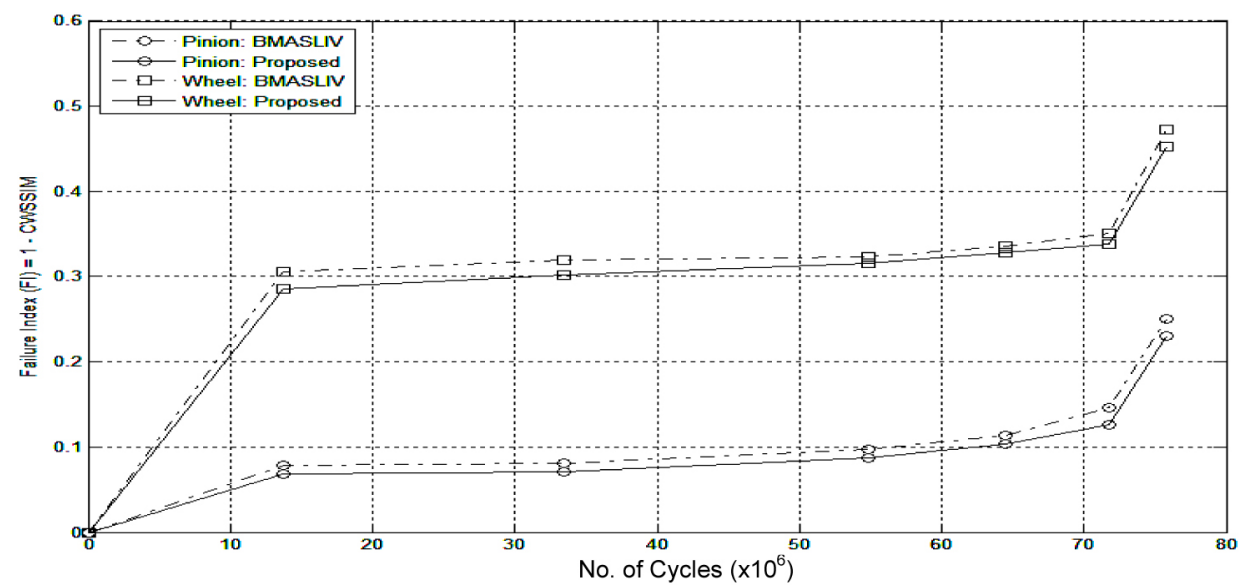

Figure 5. Failure Index (FI) values for both pinion and wheel over test period 
Table 1. Test sequence and gear damage observed

\begin{tabular}{|c|c|c|c|c|c|}
\hline $\begin{array}{l}\text { Test Day } \\
\text { No. }\end{array}$ & $\begin{array}{l}\text { Running } \\
\text { Speed } \\
\text { (rpm) }\end{array}$ & $\begin{array}{l}\text { Applied } \\
\text { Torque } \\
\text { (Nm) }\end{array}$ & $\begin{array}{c}\text { Duration } \\
\text { Cycles }\left(\mathbf{x} 10^{3}\right)\end{array}$ & $\begin{array}{c}\text { Cumulative } \\
\text { Duration } \\
\text { Cycles }\left(x 10^{3}\right)\end{array}$ & Gear Damage Observed \\
\hline \multicolumn{6}{|c|}{ Stage 1 Micro-Pitting Test } \\
\hline 1 & 1100 & 100 & 47 & 47 & \multirow{7}{*}{$\begin{array}{l}\text { Progressive micro-pitting; } \\
\text { up to } 15 \mu \mathrm{m} \text { profile deviation. }\end{array}$} \\
\hline 1 & 2000 & 100 & 63 & 110 & \\
\hline 1 & 3000 & 100 & 97 & 207 & \\
\hline 1 & 3000 & 150 & 122 & 329 & \\
\hline 1 & 3000 & 210 & 4271 & 4600 & \\
\hline 2 & 3000 & 210 & 4200 & 8800 & \\
\hline 3 & 3000 & 210 & 4900 & 13700 & \\
\hline \multicolumn{6}{|c|}{ Stage 2 Micro-Pitting Test Continued } \\
\hline $4 \& 5$ & $\begin{array}{l}1500 \\
3000 \\
3000\end{array}$ & $\begin{array}{l}100 \\
230 \\
270\end{array}$ & 7658 & 21358 & \multirow{5}{*}{$\begin{array}{l}\text { Progressive micro-pitting and } \\
\text { small-scale macro pitting }\end{array}$} \\
\hline $6 \& 7$ & 3000 & 270 & 8383 & 29741 & \\
\hline $8 \& 9$ & 3000 & 270 & 8359 & 38100 & \\
\hline $10 \& 11$ & 3000 & 270 & 8365 & 46465 & \\
\hline $12 \& 13$ & 3000 & 270 & 8345 & 54810 & \\
\hline \multicolumn{6}{|c|}{ Stage 3 Progressive Macro-Pitting and Scuffing Test } \\
\hline $14 \& 15$ & 3000 & 310 & 8351 & 63161 & \multirow{2}{*}{$\begin{array}{c}\text { Progressive macro-pitting; } \\
\text { up to } 70 \mu \mathrm{m} \text { profile deviation }\end{array}$} \\
\hline $16 \& 18$ & 3000 & 310 & 12603 & 75764 & \\
\hline 18 & 3000 & 350 & 25 & 75789 & $\begin{array}{l}\text { Scuffing (occurred due to change made to the } \\
\text { test gears lubrication condition) }\end{array}$ \\
\hline
\end{tabular}

\section{Gear metrology check on gear profile deviation}

It is evident that the flanks of the test gears scuffed significant as a result of surface fatigue during continuous running at relatively high torque/contact stress. To quantify the damage on the gear flanks, profile deviation was measured on 4 teeth per gear using a gear measuring machine. The records of gear profile measurements at the end of stage 1 of the test and at the end of stage 3 respectively are shown in Figures 6 and $\underline{7}$. The gear involute measurements confirm the results of the IR approach.

\section{B- Monitoring Gear Surface Failure using HMS}

The result of the vibration and ODA techniques has been published in [2] and can be used to compare the result of the proposed IR approach discussed in this paper. In summary, seven monitoring parameters were used in this study to monitor gear surface failures (micro-pitting, macro-pitting and scuffing) namely; vibration RMS $V_{r m s}$, vibration kurtosis $\mathrm{V}_{\mathrm{Ku}}$, cumulative ferrous debris mass $\mathrm{OD}_{\mathrm{M}}$, ferrous debris classification counts, and ferrous particles rate/min. The analysis of all the ODA indicators coincide with the vibration indicators in providing the same increasing trend of the IR approach result.

\section{CONCLUSIONS}

This paper presents a novel method for gear surface evaluation using an image registration technique in an online health monitoring system. The correlations between aligned and reference images are obtained, and a new feature - the 'failure index', FI - is defined to describe the development of micro-pitting in gears. This method is indeed cheap and capable of application. The FI results are confirmed by the gear involute measurements showed in Figures 6 and $\underline{7}$.

The results of the FI computed by the IR algorithm for both the progression of micro-pitting and surface scuffing failures correlate well with vibration and oil debris analysis indicators. The progression of micro-pitting was monitored using the RMS of vibration and three ODA indicators, namely: cumulative ferrous debris mass $O D_{M}$, ferrous particle counts and cumulative total particle counts. Scuffing failure was monitored using vibration kurtosis $V_{K u}$, and three ODA indicators, namely: cumulative ferrous debris mass $O D_{M}$, ferrous debris classification counts and ferrous particle rate/min.

All of the online ODA indicators were used to successfully monitor the progression of micro-pitting and to detect gear scuffing failure. The online ODA monitoring has the advantage over vibration monitoring in that less effort is required to extract the monitoring features. However it is still considered important to measure vibration, due to the valuable information that can be extracted. By adding the measurement of ferrous debris mass and mass rate to the information provided by the online ODA direct detection technique, a comparison of results from oil debris and vibration analysis has provided more consistent results. The results also show that ferrous debris mass, debris count, debris rate and the ferrous debris mass rate correlate well with the progression of micro-pitting and scuffing failure. This study shows promise of incorporating the image 
registration method used with the intelligent HMS. Further publications are in preparation to demonstrate the capabilities of the developed intelligent HMS.

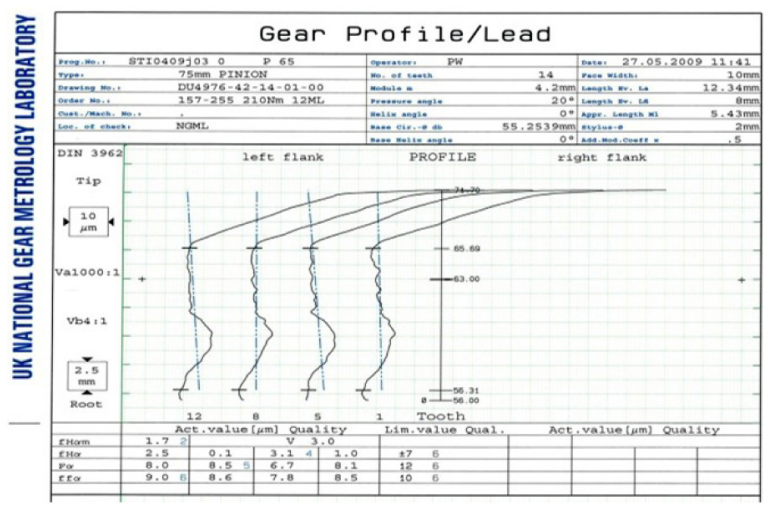

Figure 6(a). Pinion profiles of 4 teeth after test day 3. The maximum profile deviation caused by micro-pitting is evaluated as around $10 \mu \mathrm{m}$.

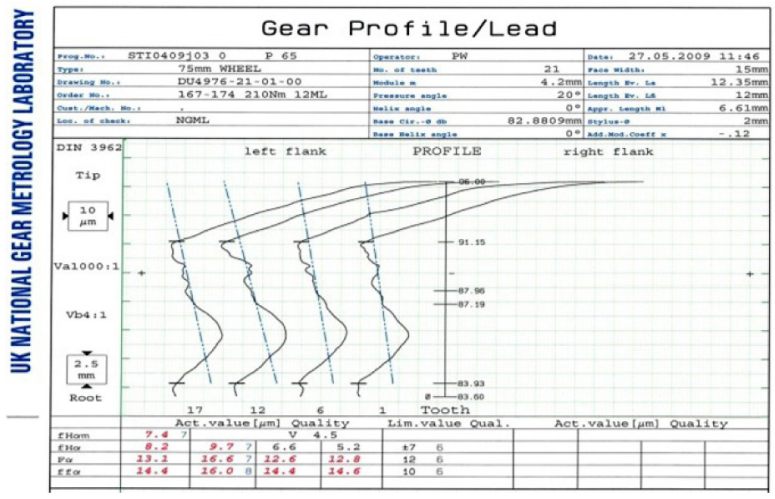

Figure 6(b). Wheel profiles of 4 teeth after test day 3 . The maximum profile deviation caused by micro-pitting is evaluated as around $15 \mu \mathrm{m}$.

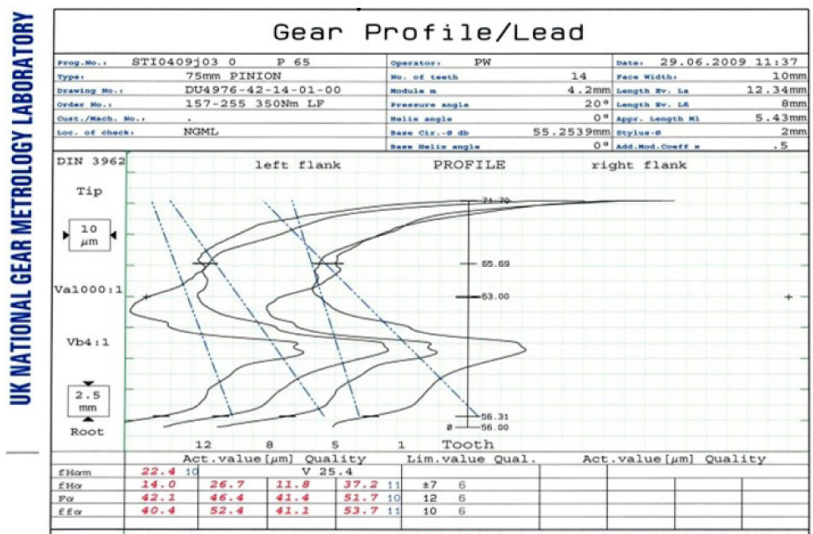

Figure $7(a)$. Pinion profiles of 4 teeth after test day 18 . The maximum profile deviation caused by micro-pitting and macro pitting is evaluated as around $50 \mu \mathrm{m}$.

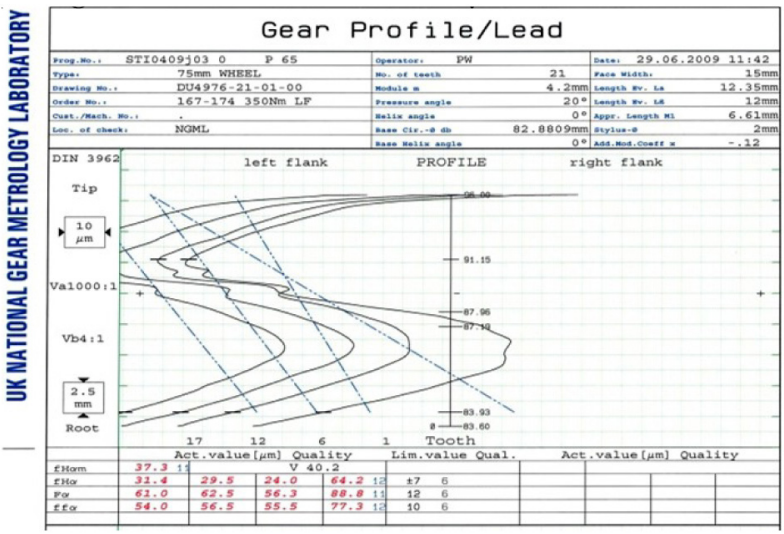

Figure $7(b)$. Wheel profiles of 4 teeth after test day 18 . The maximum profile deviation caused by micro-pitting and macro pitting is evaluated as around $70 \mu \mathrm{m}$.

\section{REFERENCES}

1. SMITH, J.D. (1983.) Gears and Their Vibration: A Basic Approach to Understanding Gear Noise, New York: M. Dekker; London: Macmillan Press.

2. Onsy, A., Shaw, B., and Zhang, J., "Monitoring the Progression of Micro-Pitting in Spur Geared Transmission Systems Using Online Health Monitoring Techniques," SAE Int. J. Aerosp. 4(2):13011315, 2011, doi:10.4271/2011-01-2700.

3. ONSY, A., BICKER, R. \& SHAW, B.A. (2010b) A Novel Intelligent Health Monitoring System for Gear Fatigue Failure Prediction. 23rd International Congress on Condition Monitoring and Diagnostic Engineering Management; COMADEM 2010, Japan, Nara, ISBN 978-4-88325-419-4.

4. ONSY, A., BICKER, R. \& SHAW, B.A. (2010a) Intelligent Diagnostic Health Management of Power Transmission Systems: An Experimental Validation. International Journal of COMADEM, Vol.13 (2) pp. 46-58, ISSN 1363-7681.

5. ONSY, A., BICKER, R., SHAW, B.A., ROWLAND, C.W. \& KENT, T. (2009) Intelligent Health Monitoring of Power Transmission Systems; An Experimental Validation. Proceedings of the 2009 Conference of the Society for Machinery Failure Prevention Technology, USA, Dayton, Ohio, 499-518.

6. Onsy, A., Bicker, R., and Shaw, B., "Predictive Health Monitoring of Gear Surface Fatigue Failure Using Model-Based Parametric Method Algorithms; An Experimental Validation," SAE Int. J. Aerosp. 6(1):1-7, 2013, doi:10.4271/2013-01-0624.

7. FOUAD, M.M., DANSEREAU, R.M. \& WHITEHEAD, A.D. (2010) Geometric image registration under locally variant illuminations using Huber M-estimator. In Elmoataz A. et al. (Eds.), Quèbec, Canada, volume LNCS 6134, 10-18. Springer, Heidelberg.

8. FOUAD, M.M., DANSEREAU, R.M. \& WHITEHEAD, A.D. (2012) Image registration under illumination variations using regionbased confidence weighted M-estimators. IEEE Transactions on Image Processing, Vol. 21, No. 3, 1046-1060.

9. ONSY, A., BICKER, R., SHAW, B.A., ROWLAND, C.W. \& KENT, T. (2008b) Monitoring Bending Fatigue Failure in Helical Gears Using Acoustic Emission, Vibration, and On-Line Oil Debris Analysis: A Comparative Study. Proceedings of the $5^{\text {th }}$ Intern. Conference on Condition Monitoring \& Machinery Failure Prevention Technologies, UK, Edinburgh.

10. ONSY, A., BICKER, R., SHAW, B.A., ROWLAND, C.W. \& KENT, T. (2008a) Monitoring the Progression of Micro-Pitting in Helical Gears: Towards an Intelligent Health Monitoring System. Paper presented at the AEWG-51 \& International Symposium on AE, USA, Memphis, Tennessee.

11. ONSY, A., BICKER, R., SHAW, B.A. \& FOUAD, M.M., (2012) Application of image registration techniques in monitoring the progression of surface fatigue failures in geared transmission systems, IEEE Aerospace Conf., Montana, USA, pp. 1-14.

12. WANG, Z. \& SIMONCELLI, E.P. (2005) Translation insensitive image similarity in complex wavelet domain. In IEEE Intern. Conf. on Acoustics, Speech, Signal Processing (ICASSP'05), Vol. II, 573-576, PA, USA. 
13. Onsy, A., "A New Acoustic Emission Wireless Monitoring System; An Experimental Validation of Bearing Condition Monitoring," $S A E$ Int. J. Aerosp. 6(2):534-539, 2013, doi:10.4271/2013-01-2221.

\section{ACKNOWLEGMENT}

The authors acknowledge the excellent collaborative efforts of the Design Unit staff at Newcastle University for their technical support during the experimental testing.

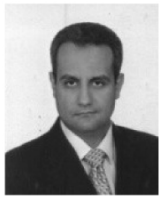

AhmedOnsy is a lecturer of smart measurement and mechatronics systems, diagnostic and maintenance engineering, MTC, Cairo, Egypt. He has been awarded his PhD from the School of Mechanical and Systems Engineering, Design Unit and Mechatronics Group, Newcastle University, UK. His research is focusing on the development of online intelligent health monitoring systems. His research is directly applied to IDHM and PHM systems for aerospace, wind turbine, marine, and automotive applications.

\section{tiphms@gmail.com.}

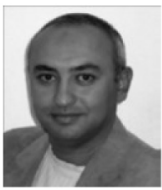

Mohamed M. Fouad received the Bachelor engineering (honors, with great distinction) and Masters' engineering degrees from MTC, Cairo, Egypt, in 1996 and 2001, respectively. As well, he received the Ph.D. degree in Electrical and Computer engineering from Carleton University, Ottawa, Ontario, Canada, in 2010. He is currently a faculty member with the Department of Computer Engineering, MTC. His research interests are in online handwritten recognition, image registration, image reconstruction, super-resolution, video compression and multiview video coding.

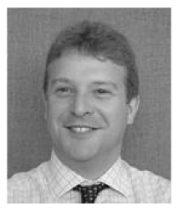

Brian Shaw is the director of Design Unit - Gear Technology Centre in the School of Mechanical and Systems Engineering. $\mathrm{He}$ is also, the Director of the British Gear Association. His research interests are linked to materials engineering for transmission components with specific interests in gear/bearing failure analysis, fatigue testing for performance characterisation and the development and use of NDT methods including Magnetic Barkhausen Emission.

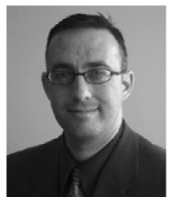

Richard M. Dansereau, received the B.Sc. and Ph.D. degrees in Computer Engineering from the Department of Electrical and Computer Engineering, University of Manitoba, Winnipeg, MB, Canada, in 1995 and 2001, respectively. From 1999 to 2000, he was also with SpectraWorks, Inc. From 2000 to 2001, he was an Instructor and Research Engineer in the Department of Electrical and Computer Engineering at the Georgia Institute of Technology, Atlanta, GA. In September 2001, he joined the Department of Systems and Computer Engineering, Carleton University, ON, Canada, where he is currently an Associate Professor. All rights reserved. No part of this publication may be reproduced, stored in a retrieval system, or transmitted, in any form or by any means, electronic, mechanical,
photocopying, recording, or otherwise, without the prior written permission of SAE International. 